\title{
Risk Factors for Revision After Early and Delayed Total Hip Arthroplasty Dislocation. An Analysis of Lithuanian Arthroplasty Register
}

Povilas Masionis ${ }^{1}$, Tomas P. Vileikis ${ }^{2}$, Giedrius Kvederas ${ }^{1}$, Valentinas Uvarovas ${ }^{3}$, Igoris Šatkauskas ${ }^{3}$, Tomas Sveikata $^{3}$, Jaunius Kurtinaitis ${ }^{3}$

1. Centre of Orthopedics and Traumatology, Vilnius University Hospital Santaros Clinics, Vilnius, LTU 2. Centre of Orthopedics and Traumatology, Faculty of Medicine, Vilnius University, Vilnius, LTU 3. Centre of Orthopedics and Traumatology, Republican Vilnius University Hospital, Vilnius, LTU

Corresponding author: Povilas Masionis, povilasmasionis@yahoo.com

\begin{abstract}
Introduction: Despite relatively low incidence, dislocation remains one of the main reasons for total hip arthroplasty (THA) revision. It is a devastating complication for a patient and a surgeon, and has high burden on the healthcare system. The aim of the present study was to assess and compare the risk factors for revision after early and delayed THA dislocations.
\end{abstract}

Methods: Some 3403 THA through posterior approach for primary osteoarthritis were retrospectively studied in the Lithuanian Arthroplasty Register from 2011 to 2018. Three months after THA was the splitting time between the first event of early and delayed dislocations. Revision was set as outcome measure. Gender, affected side, number of dislocations, femoral head and neck size, and prosthesis fixation type were tested as risk factors for revision after early and delayed THA dislocations.

Results: Dislocation occurred in 108 patients (3.2\%), and 26 cases (0.8\%) required revision. Men had statistically significant higher risk for revision due to early dislocation [hazard ratio (HR) 4.7 ; 1.3-17.7 confidence interval (CI)] and considerably lower risk for revision due to delayed dislocation (HR 0.5; 0.1-1.7 $\mathrm{CI}$ ). The left side THA had twice the risk as compared to the right in the early settings (HR 2.1; 0.6-6.9 CI) which equalized after three months (HR 1.1; 0.4-3.1 CI). Some $32 \mathrm{~mm}$ femoral head had significantly lower risk in the early group as compared to $28 \mathrm{~mm}$ head (HR 0.3; 0.1-0.5 CI). Short head was associated with increased risk for revision after early dislocation, although, not statistically significant. Prosthesis fixation type was not a risk factor for revision surgery neither after early nor after delayed dislocation.

Conclusion: The unique finding of gender separation was found -- men tend for revision after early dislocation and women after delayed dislocation. In early stage, additional precautions should be considered when $28 \mathrm{~mm}$ short metal heads are used.

Review began 02/27/2021 Review ended 03/16/2021 Published 03/28/2021

\section{() Copyright 2021}

Masionis et al. This is an open access article distributed under the terms of the Creative Commons Attribution License CC-BY 4.0., which permits unrestricted use, distribution, and reproduction in any medium, provided the original author and source are credited.
Categories: Orthopedics, Other

Keywords: tha, dislocation, revision, arthroplasty, register

\section{Introduction}

With an aging population and growing demand for improved mobility and life quality in the increased cases of arthritis, joint replacement surgery is believed to become the most common elective surgical procedure in the following decades [1]. It is indicated in the United States that the number of patients with total joint replacement is similar to the number of patients with public's attention catching chronic diseases, such as stroke or myocardial infarction and that the prevalence of total joint replacement is considerably higher than heart failure [1]. Dislocation in total hip arthroplasty (THA) is one of the most common reason for revision and has the incidence from $0.3 \%$ to $10 \%$ [2-3]. It is the most common cause of revision in the United states and the second after aseptic loosening in Swedish and France [2, 4]. A similar situation can be seen in Lithuania, where $66.2 \%$ of all revisions after THA are performed due to recurrent dislocations [5]. It is a devastating complication for a patient and a surgeon and has a high burden on the healthcare system [6]. Prevention of dislocation starts with thoughtful preoperative planning and assessment, surgical precision, and good postoperative care. However, about 60\% of dislocated THA will relapse and 50\% will require revision surgery [7]. If great trochanter is not significantly displaced, there is no visible component malposition or failed closed reduction, revision surgery is considered after two or even three dislocation episodes [8]. Risk factors for THA to dislocate are well known and classified to patient, surgeon and implant related, but risk factors for revision after dislocation remain unknown. Therefore, aim of the present study was to assess the risk factors for revision after early and delayed dislocations after THA.

\section{Materials And Methods}

Data were extracted from the Lithuanian Arthroplasty Register and included the period from January 1, 2011 


\section{Cureus}

to December 31, 2018. Some 5689 patients who went through THA were retrospectively studied. All patients, who were involved in a study, underwent primary THA through posterolateral approach (described by Moore) for primary arthrosis in the single institution [9]. Exclusion criteria were: revision THA, THA for femoral neck fracture, and stable THA. THA through direct anterior and direct lateral approaches were excluded because of the low sample size and the absence of dislocations. Patients who underwent surgery with the implant heads of a rarely used diameter $(24,26,30$, and $40 \mathrm{~mm})$ were not included in the study. Cases of dual mobility or constrained cup were not included. Excluding patients according to above mentioned criteria, our final sample size was 108 patients (Figure 1).

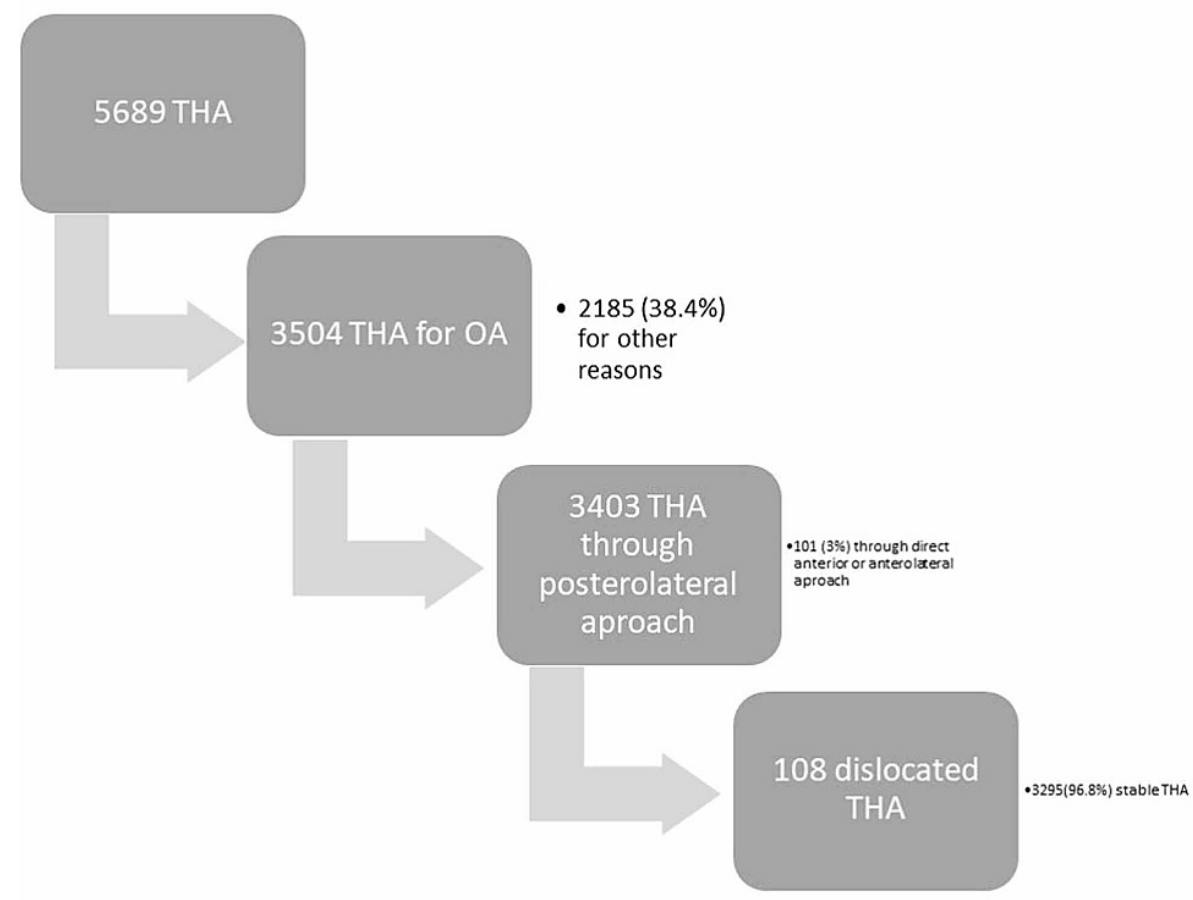

FIGURE 1: Flow diagram of patient exclusion and the final sample size.

Experienced radiologist evaluated THA X-rays (in cases of revision prerevision X-rays) for the following criteria: cup anteversion and inclination, femoral offset difference, and leg length discrepancy (LLD). The patient demographics and radiological parameters according to study groups are presented in Table 1 . The patients were distributed according to the normal distribution by gender, age, side which was operated, and radiological parameters. In the study, the term 'revision' was defined as an open intervention where the whole prosthesis was eliminated, where an augmentation device was added, or where one or more parts of the implant were exchanged. Dislocations after THA (first occurrence) were divided into early and delayed. Some 90 days after THA was the splitting time between the incidence of early and delayed dislocations [10]. 


\section{Cureus}

\begin{tabular}{|c|c|c|c|c|c|}
\hline \multirow{2}{*}{$\begin{array}{l}\text { Variables } \\
\text { Gender (male/female) }\end{array}$} & \multicolumn{2}{|c|}{ Early dislocation group $(\mathrm{N}=43$ ) } & \multicolumn{2}{|c|}{ Delayed dislocation $(\mathrm{N}=65)$} & \multirow{2}{*}{$\begin{array}{l}\text { p value } \\
0.66\end{array}$} \\
\hline & 17 & 26 & 23 & 41 & \\
\hline Age (years) & \multicolumn{2}{|c|}{$68 \pm 11$} & \multicolumn{2}{|c|}{$67 \pm 10$} & 0.63 \\
\hline Operated side (right/left) & 25 & 18 & 44 & 21 & 0.31 \\
\hline Cup anteversion (degrees) & \multicolumn{2}{|c|}{$23.97 \pm 8.37$} & \multicolumn{2}{|c|}{$21.37 \pm 7.59$} & 0.13 \\
\hline Cup inclination (degrees) & \multicolumn{2}{|c|}{$46.94 \pm 9.30$} & \multicolumn{2}{|c|}{$46.63 \pm 7.05$} & 0.86 \\
\hline Femoral offset difference (mm) & \multicolumn{2}{|c|}{$0.28 \pm 5.35$} & \multicolumn{2}{|c|}{$0.81 \pm 7.98$} & 0.73 \\
\hline $\operatorname{LLD}(\mathrm{mm})$ & \multicolumn{2}{|c|}{$3.21 \pm 7.90$} & \multicolumn{2}{|c|}{$2.66 \pm 8.73$} & 0.77 \\
\hline
\end{tabular}

\section{TABLE 1: Comparison of demographics and radiological parameters between early and delayed}

dislocation groups.

LLD, leg length discrepancy

Follow-up of patients began on the day when primary THA was performed and ended on the day of revision, emigration, death or December 31, 2018, whichever came first. Where appropriate median values, ranges, means, and 95\% confidence interval (CI) were used by continuous descriptive statistics. Cox regression models were used to generate hazard ratio (HR) and its 95\% CIs for various covariates, such as gender, head type, head size, head length, fixation method, and affected side. The level of significance was set at $\mathrm{p}<0.05$ in all analyses and we used IBM SPSS 22.0 (IBM Corp, Armonk, NY, USA) statistical package for data analysis.

\section{Results}

At follow-up out of 3403 primary THA dislocation occurred in 108 patients (3.2\%), of which 26 cases $(0.8 \%)$ had been revised. The first dislocation in 65 cases (60.2\%) occurred later than three months after THA, while 43 (39.8\%) dislocations occurred during the first three months. Some 14 (32.6\%) early dislocations and 12 (18.5\%) delayed dislocations required revision. The mean time from THA to revision surgery in the early dislocation group was $31.1 \pm 21.2$ days and $2.7 \pm 2$ years in delayed group. No statistically significant difference was observed in early and delayed dislocation groups in terms of degree of cup anteversion (23.97 \pm 8.37 and $21.37 \pm 7.60, \mathrm{p}=0.13$ respectively), the degree of cup inclination $(46,94 \pm 9,30$ and $46,63 \pm 7,05, \mathrm{p}=$ $0.86)$, the difference of femoral offset between both legs in millimeters $(0.28 \pm 5.35$ and $0.81 \pm 7.98, p=0.73)$, and $\operatorname{LLD}(3.21 \pm 7.90$ and $2.66 \pm 8.73, \mathrm{p}=0.77)$.

By entering all mentioned covariates into a multiple regression model, adjusted HRs were calculated (Table 2). In the Cox regression analysis, risk of revision due to early dislocation was statistically significantly higher in males than in females (HR 4.7; $1.3-17.7 \mathrm{CI}, \mathrm{p}=0.02$ ), while risk of revision due to delayed dislocation was considerably lower in men (HR 0.5; 0.1-1.7 CI, $p=0.26$ ). The risk of revision after early dislocations of the left side THA was twice as high as the risk of the right side (HR 2.1; 0.6-6.9 CI p = 0.22 ), even though the risk equalized after three months (HR $1.1 ; 0.4-3.1 \mathrm{CI} p=0.84$ ). We found a statistically significantly lower risk of revision due to early dislocation when using $32 \mathrm{~mm}$ head diameter than compared to $28 \mathrm{~mm}$ head [HR 0.3 ; 0.1-0.5 (CI p = 0.04)] and that ceramic heads in group of patients with early dislocation were associated with reduced risk of revision in comparison to metal heads [HR 0.6; (0.1-2.8 CI p $=0.51)]$. An increasing head length of an implant also showed a reduction in risk of revision after early dislocation, with the lowest risk being observed when using long heads [0.3; $(0.5-1.9 \mathrm{CI}) \mathrm{p}=0.21]$, however, this observation was not statistically significant. Finally, we did not find any statistically significant evidence that the type of fixation (cemented or uncemented) affected the risk of revision after early [1.1; $(0.2-4.9 \mathrm{CI}) \mathrm{p}=0.95]$ or late $[1.2 ;(0.3-4.4 \mathrm{CI}) \mathrm{p}=0.76]$ dislocation. 


\begin{tabular}{|c|c|c|c|c|c|c|c|}
\hline \multirow{2}{*}{ Group factor } & & \multicolumn{3}{|c|}{ Revision after early dislocation } & \multicolumn{3}{|c|}{ Revision after delayed dislocation } \\
\hline & & HR & $\mathrm{Cl}$ & $\mathrm{p}$ value & HR & $\mathrm{Cl}$ & $p$ value \\
\hline \multirow{2}{*}{ Gender } & Female & 1 & & & 1 & & \\
\hline & Male & 4.7 & $1.3-17.7$ & 0.02 & 0.5 & $0.1-1.7$ & 0.26 \\
\hline \multicolumn{2}{|l|}{ Number of dislocations } & 1.2 & $0.8-1.8$ & 0.49 & 1.3 & 1.0-1.7 & 0.06 \\
\hline \multirow[b]{2}{*}{ Head type } & Metal & 1 & & & & 1 & \\
\hline & Ceramic & 0.6 & $0.1-2.8$ & 0.51 & 1.0 & $0.3-3.2$ & 0.99 \\
\hline \multirow{3}{*}{ Head size } & $28 \mathrm{~mm}$ & 1 & & & 1 & & \\
\hline & $32 \mathrm{~mm}$ & 0.29 & $0.1-0.5$ & 0.04 & 0.9 & $0.3-2.8$ & 0.83 \\
\hline & $36 \mathrm{~mm}$ & 0 & & & 1.3 & $0.1-11.6$ & 0.83 \\
\hline \multirow[b]{2}{*}{ Fixation } & Cemented & 1 & & & 1 & & \\
\hline & Uncemented & 1.1 & $0.2-4.9$ & 0.95 & 1.2 & $0.3-4.4$ & 0.76 \\
\hline \multirow{3}{*}{ Head length } & Short & 1 & & & 1 & & \\
\hline & Medium & 0.8 & $0.2-3.0$ & 0.69 & 2.1 & $0.5-9.9$ & 0.34 \\
\hline & Long & 0.3 & $0.5-1.9$ & 0.21 & 1.0 & $0.2-5.6$ & 0.98 \\
\hline \multirow[b]{2}{*}{ Affected side } & Right & 1 & & & 1 & & \\
\hline & Left & 2.1 & $0.6-6.9$ & 0.22 & 1.1 & $0.4-3.1$ & 0.84 \\
\hline
\end{tabular}

TABLE 2: HR, 95\% CI, and p values of different factors for revision after early and delayed dislocation.

$\mathrm{HR}$, hazard ratio; $\mathrm{Cl}$, confidence interval

\section{Discussion}

The purpose of this paper was to estimate, whether revisions after early and delayed dislocations have the same risk factors, using data from the Lithuanian Arthroplasty Register -- gender and femoral head size were found as statistically significant factors separating revision risk after early and delayed dislocations.

The overall dislocation rate in our study was 3.2\%, which is comparable to other reports [2-3]. Moreover, similar dislocation rate was found in the study by Woolson et al., in which 10,500 THAs were performed and the incidence in Italy is studied to be from $0.3 \%$ to $10 \%$ [11-12].

After adapting for THA and patient characteristics, our analysis shows that male gender is related to a significant higher risk of revision after early dislocation and considerably lower risk of revision due to delayed dislocation after THA. In literature we found little evidence about gender as a risk factor for revision after dislocation. An article by Hailer et al., stated that males have a higher risk for revision after dislocation after THA, but there was no distinction between early and delayed dislocations [4]. Recently, Rowan et al. wrote that neither of sex, simultaneous bilateral THA, or restrictive postoperative precautions have an impact on dislocation rates after THA [13]. We could not find any literature about the risk factors for revision after early and delayed dislocations, therefore, this finding is unique.

We did not find any literature about the influence of the operated side on the risk for revision. Even though we saw a tendency that the risk for revision after early dislocations of the left side was twice as high as the 
risk of the right side, our finding was not statistically significant. There is no literature on THA and dominant leg, but there are some reports on muscle strength difference and its clinical implication of dominant leg [14-15]. In our opinion, the impact of dominant leg on total joint arthroplasty outcomes is a hypothesis for further studies.

We chose a three-month period as the distinguishing point between early and delayed dislocations, because dislocations usually occur within a period of three months after THA. Up to 70\% of dislocations occur during the first month after surgery or up to 66\% occur during first five weeks [16-17]. Dislocations that happen within 0-3 months from surgery, usually occur due to patient factors, deficiency of mature scar tissue or tension in soft tissue, while delayed dislocations are most often caused by component malposition or polyethylene wear [10]. A study by Peters et al. shows that $93 \%$ of orthopedic departments in the Netherlands use patient restrictions following posterolateral approach THA [18]. In our clinic, the restriction period and rehabilitation process after posterolateral approach THA lasts for three months. Similar recommendations are described by Zahar et al., that for patients after THA rotation, flexion over $90^{\circ}$ and adduction of the hip should be limited by the brace for six weeks, after that each motion modality should be gradually increased, while internal rotation and adduction should still be avoided for three months after operation. Therefore, dislocations that occurred after the end of rehabilitation period were considered delayed [19].

Our findings that head diameter of $32 \mathrm{~mm}$ is associated with lower risk of revision after early dislocation as compared to $28 \mathrm{~mm}$ head diameter are similar to what was stated by Conroy et al. and Girarg et al., that the increase of head size reduces the risk of revision [20-21]. Furthermore, we only analyzed THA done through posterolateral approach -- direct anterior and lateral approaches were excluded because of absence of dislocations and low sample number. Further, Pedneault et al. found that attention to surgical technique with posterior capsular closure outweighs the importance of femoral head size through posterolateral approach [22]. Although, the Lithuanian register of joint arthroplasty does not account the fact of whether the posterior capsule was reconstructed or not. Because of this reason, the question remains if the revision after early dislocation is associated with smaller femoral head or with unreconstructed posterior capsule.

In this study, there are some potential limitations that should be considered. First of all, it is a single institution experience extracted from the National Arthroplasty Register and it might be questionable if the results could be applied nationwide. Second, in our analysis we could not adjust for such variables, as patient BMI, activity levels, comorbidities, neurological disability, prosthetic malposition, implant impingement, hip anatomy restoration, alcohol abuse and mental status, and therefore could not assess patient demand on the implant. These variables were not available from the Lithuania Arthroplasty Register.

\section{Conclusions}

The gender separation was found -- men tend for revision after early dislocation and women after delayed dislocation. The risk for the revision after early dislocation is twice higher when left hip was operated, although, clinical implication of this finding remains unclear. In early stage, additional precautions should be considered when $28 \mathrm{~mm}$ short metal heads are used.

\section{Additional Information \\ Disclosures}

Human subjects: Consent was obtained or waived by all participants in this study. Animal subjects: All authors have confirmed that this study did not involve animal subjects or tissue. Conflicts of interest: In compliance with the ICMJE uniform disclosure form, all authors declare the following: Payment/services info: All authors have declared that no financial support was received from any organization for the submitted work. Financial relationships: All authors have declared that they have no financial relationships at present or within the previous three years with any organizations that might have an interest in the submitted work. Other relationships: All authors have declared that there are no other relationships or activities that could appear to have influenced the submitted work.

\section{References}

1. Maradit Kremers H, Larson DR, Crowson CS, et al.: Prevalence of total hip and knee replacement in the United States. J Bone Joint Surg - Am Vol. 2015, 97:1386-1397. 10.2106/JBJS.N.01141

2. Bozic KJ, Kurtz SM, Lau E, Ong K, Vail TP, Berry DJ: The epidemiology of revision total hip arthroplasty in the United States. J Bone Joint Surg Am Vol. 2009, 91:128-133. 10.2106/JBJS.H.00155

3. Werner BC: Instability after total hip arthroplasty. World J Orthop. 2012, 3:122-130. 10.5312/wjo.v3.i8.122

4. Hailer NP, Weiss RJ, Stark A, Kärrholm J: The risk of revision due to dislocation after total hip arthroplasty depends on surgical approach, femoral head size, sex, and primary diagnosis: an analysis of 78,098 operations in the Swedish Hip Arthroplasty Register. Acta Orthop. 2012, 83:442-448. 10.3109/17453674.2012.733919

5. Tarasevičius Š, Čebatorius A, Valavičienė R, Stučinskas J, Leonas L, Robertsson O: First outcome results after total knee and hip replacement from the Lithuanian arthroplasty register. Medicina. 2014, 50:87-91. 10.1016/j.medici.2014.06.004

6. Abdel MP, Cross MB, Yasen AT, Haddad FS: The functional and financial impact of isolated and recurrent dislocation after total hip arthroplasty. Bone Joint J. 2015, 97:1046-1049. 10.1302/0301-620X.97B8.34952 
7. Lu Y, Xiao H, Xue F: Causes of and treatment options for dislocation following total hip arthroplasty (Review). Exp Ther Med. 2019, 3:1715-1722. 10.3892/etm.2019.7733

8. Charissoux J-L, Asloum Y, Marcheix P-S: Surgical management of recurrent dislocation after total hip arthroplasty. Orthop Traumatol Surg Res. 2014, 100:25-34. 10.1016/j.otsr.2013.11.008

9. Moore AT: The self-locking metal hip prosthesis. J Bone Joint Surg. 1957, 39:811-827.

10. Daly P, Morrey B: Operative correction of an unstable total hip arthroplasty. J Bone Joint Surg. 1992, 74:1334-1343.

11. Woolson ST, Rahimtoola ZO: Risk factors for dislocation during the first 3 months after primary total hip replacement. J Arthroplasty. 1999, 14:662-668. 10.1016/S0883-5403(99)90219-X

12. Falez F, Papalia M, Favetti F, Panegrossi G, Casella F, Mazzotta G: Total hip arthroplasty instability in Italy . International Orthopaedics (SICOT). 2017, 41:635-644. 10.1007/s00264-016-3345-6

13. Rowan FE, Benjamin B, Pietrak JR, Haddad FS: Prevention of dislocation after total hip arthroplasty . J Arthroplasty. 2018, 33:1316-1324. 10.1016/j.arth.2018.01.047

14. Lanshammar K, Ribom EL: Differences in muscle strength in dominant and non-dominant leg in females aged 20-39 years - a population-based study. Phys Ther Sport. 2011, 12:76-79. 10.1016/j.ptsp.2010.10.004

15. Promsri A, Haid T, Federolf P: How does lower limb dominance influence postural control movements during single leg stance?. Hum Movement Sci. 2018, 58:165-174. 10.1016/j.humov.2018.02.003

16. Vajapey SP, Fideler KL, Lynch D, Li M: Use of dual mobility components in total hip arthroplasty: Indications and outcomes. J Clin Orthop Trauma. 2020, 11:760-765. 10.1016/j.jcot.2020.07.035

17. Ali Khan M, Brakenbury P, Reynolds I: Dislocation following total hip replacement. J Bone Joint Surg Br Vol. 1981, 63:214-218. 10.1302/0301-620X.63B2.7217144

18. Peters A, Veldhuijzen AJH, Tijink M, Poolman RW, Huis In 't Veld RMHA: Patient restrictions following total hip arthroplasty: a national survey. Acta Orthop Belg. 2017, 83:45-52.

19. Zahar A, Rastogi A, Kendoff D: Dislocation after total hip arthroplasty. Curr Rev Musculoskelet Med. 2013, 6:350-356. 10.1007/s12178-013-9187-6

20. Conroy JL, Whitehouse SL, Graves SE, Pratt NL, Ryan P, Crawford RW: Risk factors for revision for early dislocation in total hip arthroplasty. J Arthroplasty. 2008, 23:867-872. 10.1016/j.arth.2007.07.009

21. Girard J, Kern G, Migaud H, Delaunay C, Ramdane N, Hamadouche M: Primary total hip arthroplasty revision due to dislocation: prospective French multicenter study. Orthop Traumatol Surg Res. 2013, 99:549553. 10.1016/j.otsr.2013.03.026

22. Pedneault C, Tanzer D, Nooh A, Smith K, Tanzer M: Capsular closure outweighs head size in preventing dislocation following revision total hip arthroplasty. HIP Int. 2020, 30:141-146. 10.1177/1120700019848107 